\title{
Validating the Need to Include the Economic Returns of Graduates as a Metric of a Higher Education Institutions Level of Sustainability
}

\author{
Antonios Maragakis ${ }^{1}$, Andy van den Dobbelsteen ${ }^{1} \&$ Alexandros Maragakis $^{2}$ \\ ${ }^{1}$ Delft University of Technology, Faculty of Architecture and the Built Environment, Department of Architectural \\ Engineering + Technology, P.O. Box 5043, 2600 GA Delft, The Netherlands \\ 2 Department of Psychology, Eastern Michigan University, Ypsilanti, MI 48197, USA \\ Correspondence: Antonios Maragakis, Delft University of Technology, Faculty of Architecture and the Built \\ Environment, Department of Architectural Engineering + Technology, P.O. Box 5043, 2600 GA Delft, The \\ Netherlands
}

Received: September 19, 2016

Accepted: October 24, $2016 \quad$ Online Published: October 28, 2016

doi:10.5430/ijhe.v5n4p237

URL: http://dx.doi.org/10.5430/ijhe.v5n4p237

\begin{abstract}
Higher education institutions play an important role in sustainability, in their own management and operation, in research and education, and in the undergraduate and graduate degrees they deliver. Often ignored, economic sustainability and future perspectives of students are important indicators too. The research presented in this paper validates that a student's post-graduation economic performance should be part of a higher education institution's metric for sustainability. The data collected in this research, as well as in other research, shows that almost $90 \%$ of respondents agree that economic metrics should be considered part of a higher education institutions level of sustainability. While there is no doubt about the economic gains of higher education, the results indicate that students utilizing a manageable $8 \%$ repayment of economic debt would be in debt for decades after graduation, further supporting the need for institutions to inform their stakeholders before such a life changing commitment.
\end{abstract}

Keywords: Sustainable Development, Higher Education, Universities, Sustainable Education, Sustainable Assessment

\section{Introduction}

Higher education has seen a steady use of the term sustainability since the Talloires Declaration (1990). Since then, thirteen major international declarations have been created to support this process and a steady stream of sustainability assessment tools to support them. Policy makers (UNESCO, 2011) and students (Bone \& Agombar, 2011) have placed a significant emphasis on sustainability within higher education and institutions have responded by actively implementing sustainable initiatives. With all these initiatives, focus and subsequent marketing, there is still no clear definition as to what sustainability means as applied to higher education institutions.

Rather than trying to define the term in relation to higher education, Maragakis \& Dobbelsteen (2013) conducted a survey to understand what stakeholders looked for in sustainable institutions. The empirical data collected suggested that one of the gaps in current assessment systems is the lack of economic parameters, namely "employability" after graduation.

However, employability is a convoluted term. Employability is more than just obtaining work; a literature review by Maragakis et al. (2016a) recommended that three criteria should be used to assess one's employability due to their importance to future job-seeking graduates:

1. Starting salary, as it was highly correlated to mid-career salary levels (Rajecki \& Borden, 2011),

2. Under-employment, which is defined as part-time work when full-time work is desired, as it has become a growing concern after the financial crisis of 2008 (Ashford et al., 2012), and

3. Over-education, which is defined as being overqualified for the employment position, as this is also a growing phenomenon (Carroll \& Tani, 2013).

These three criteria were further explored by Maragakis et al. (2016b) to gain insight on the perceptions held by higher education stakeholders. The data collected indicated that there was a strong preference for students to be employable after graduation, although students where not particularly concerned with starting salary or 
under-employment. Stakeholders also had a strong preference regarding the relatively value of higher education as an investment: specifically that education should cost less than $15 \%$ of their future wages while also taking less than 10 years to repay.

This research intends to bridge the gap between the economic expectations and realities of higher education and validate the need for economic metrics to be used when assessing a higher education institutions level of sustainability. Combining economic metrics with current sustainability assessments is a novel concept although the economics surrounding the returns of higher education have been studied thoroughly over the last several decades (Psacharopoulos \& Patrinos, 2004). This research aims to identify the need based both on stakeholder's requirements and also through data that suggests that the economic burden of higher education is unsustainable.

\section{Background}

This paper focuses on validating empirical research regarding the metrics used for reporting sustainability in higher education institutions. This research specifically looks to explore the inclusion of post-graduate economic returns as part of a higher education institutions measurement of sustainability.

In 2013, Maragakis \& Dobbelsteen's empirical evidence indicated that economic factors were a major motivation for students to pursue a degree in higher education.

Of the students pursuing higher education, $71 \%$ said they were doing it for personal accomplishment and future employability, $22 \%$ said they were studying exclusively for future employability, while only $7 \%$ responded to studying either exclusively for personal accomplishment or for some other reason. This result shows the importance of economic factors surrounding the attainment of a degree. In fact, in another questions $80 \%$ of stakeholders agreed that an institution's ability to make you more competitive in the job market is more important than sustainability. Of the remaining $20 \%$, it was repeatedly mentioned that the two factors are intertwined and thus inseparable.

The same study also identified the need of economic factors to be used as a measure of sustainability. $92 \%$ of participants identified that employability after graduation should be included in the measurement of institution's sustainability.

Maragakis \& Dobbelsteen (2015) proposed a framework for comparing sustainability assessment utilizing parameters and criteria set forth by other researchers in the field of sustainability in higher education. Utilizing this framework they compared two popular sustainability assessments. The primary focus of the research identified STARS as an assessment that would be a better basis for a universal assessment system while also highlighting that neither popular method tracked "what graduates are doing in the world," a criteria set for by Orr (Penn State Green Destiny Council, 2000). While this criteria was not specific to the employability of the graduate, it shares some commonality with post-graduate metrics on the economic reality of a graduate.

Maragakis et. al. (2016a) studied the importance of understanding the economic returns of higher education within the framework of sustainability assessment. A degree should not be marketed as sustainable unless it addresses the economic return of the future graduate. The research proposed three criteria for assessing the economic sustainability of an institution; starting salaries (based on studies from Rajecki \& Borden, 2011), employment (based on studies from Bell \& Blanchflower, 2011 and Ashford et al. 2012) and over education (based on studies from Carroll \& Tani, 2013 and Linsley, 2005).

Maragakis et. al. (2016b) showed that, at an absolute level, the stakeholder's response shows a clear preference placed on employment. The data supports a trend that a majority of the stakeholder in higher education expect a graduate to secure full-time employment. This supports the empirical data results from Maragakis \& Dobbelsteen (2013) that stakeholders were primarily focused on employability and is also validated by the OECD (2011) data showing that the employment rate for tertiary education is $27 \%$ higher than for those who have not completed an upper secondary education.

Even though the employment metrics was strongly supported, both starting salary and over-education were met with mixed opinion with respondents not showing an unequivocal preference. This relative uncertainty contradicts the strong expectations regarding both payback period and future allocation of funds regarding the debt incurred to obtain a higher education. More than $90 \%$ supported that education should cost less than $15 \%$ of their future wages while $90 \%$ supported that they should be in debt for less than 10 years. This response, when compared specifically to the relative apathy towards starting salary, hints at a gap in stakeholder's expectation versus realities. 


\section{Methodology}

\subsection{Research Question}

The primary question of this research is to validate if a student's post-graduation economic performance should be part of a higher education institutions metric for sustainability. This was done by collecting data from stakeholder which:

1. Asked stakeholders directly: "Should a student's economic well-being be a measure of a higher education institutions sustainability?"

2. Gathered data on stakeholder economic realities for before, during and after higher education and identifying any unsustainable trends.

The secondary research question was to validate the need for this metric by comparing previous perceptions with real data provided by stakeholders.

\subsection{Website}

The domain www.sustainingeducation.com was purchased and a website was developed using Wordpress. The website was developed to be focused on data collection while offering users relevant reference material. Four webpages were created:

1. An overview page with a general introduction and explanation.

2. An economic calculator page which was driven by a custom widget that collected data while computing "real-time" results from visitors that used the calculator.

3. An assessment webpage which allowed users to rate popular sustainability assessments based on fourteen different criteria.

4. A resources page which gave links to supporting material and other useful resources.

Upon completion of the website, two weeks of testing were conducted in order to debug the site and respond to problems. Small changes were made to improve user interface across various platforms (desktop, tablet, and mobile). The total time for development and testing took three months.

\subsection{Calculator Outline}

The economic calculator utilized a custom widget which was programmed to run various equation and give live results to visitors while also collecting data. The calculator fields are outlined in Table 1 and summarize the Field\#, Title, Description and Function.

Table 1. Calculator overview

\begin{tabular}{llll}
\hline Field \# & Title & Description & Function \\
\hline Field 1 & Currency & Some key currencies were None \\
& included to increase user \\
& interface by adding a currency \\
& symbol in front of the numerical \\
& values
\end{tabular}

Field 2

How much will your education cost you?

Field 3
Will you be taking out

a loan for your education?
Manual input by user of a numeric number much the education will cost to be factored into the total cost of education (capital + opportunity cost)

This is to identify how many respondents are looking to take out loans for their education. 
Field 4

Field 5

Field 6

Field 7

Field 8

Field 9

Field 10

Field 11
Loan Rate

How many years will your education take?

WITHOUT further education, what is your current/expected yearly compensation (salary plus benefits)?

WITH further education, what is your current/expected yearly compensation (salary plus benefits)?

Will you be working during your education?

Drop down menu of Yes or No

Should a student' economic well-being be a measure of a higher education institutions sustainability?
Drop down menu of Full -Time, Part -Time or No-I will not be working

Manual input by user of a This is to identify the loan numeric number

Manual input by user of a numeric number

Manual input by user of a numeric number

Manual input by
numeric number rate of respondents. It is assumed to be a fixed rate loan at the amount declared by the respondent.

This is to identify how much opportunity cost the education will require (Field 5 x Field 6 x Field 8)

This is the establish the base salary for a comparison of opportunity cost

This is to establish future salaries used for repayment of total cost of education (capital + opportunity costs)

This field captures a high the high level opportunity cost of the education. This defaults to assume:

Full - Time Employment = No loss based on current/expected salary Part - Time Employment $=$ $50 \%$ loss based on current/expected salary multiplied by years to complete education $\mathrm{No}=100 \%$ loss based on current/expected salary multiplied by years to complete education

This is to collect data for the primary purpose of this research, which was to validate if students believe if the economic metrics of higher education should be included in sustainability metrics of higher education institutions.

Drop down menu of Male or This is to identify gender Female

Drop down menu of $\mathrm{N}$. This is to identify location America, S. America, Europe, Australia, Asia and Africa 
Field 12

Field 13

Field 14

Field 15

Field 16

Field 17

Field 18

Field 19

Field 20
Academic Standing

Calculator button

At $5 \%$ of your future salary:

At $15 \%$ of your future salary:

At $25 \%$ of your future salary:

At $75 \%$ of your future salary:

Monthly payment required to pay back educational investment in 5 years:

Monthly payment required to pay back educational investment in 15 years:

Monthly payment required to pay back educational investment in 30 years:
Drop down menu of Future First Time Student, Undergraduate student, Graduate/post graduate student, Professional considering further education, Other.

Calculate

How many years it will take to pay back the total debt (including opportunity cost) at the level of the predicted future salary

How many years it will take to pay back the total debt (including opportunity cost) at the level of the predicted future salary

How many years it will take to pay back the total debt (including opportunity cost) at the level of the predicted future salary

How many years it will take to pay back the total debt (including opportunity cost) at the level of the predicted future salary

How much money it will take to pay back the total debt (including opportunity cost) for the years identified in the title

How much money it will take to pay back the total debt (including opportunity cost) for the years identified in the title

How much money it will take to pay back the total debt (including opportunity cost) for the years identified in the title
This is to identify the type

of respondent

This button calculates Fields 1 through 13 and returns the results in field 14 through 20

This informs the user of the results calculated from their inputs of the above fields

This informs the user of the results calculated from their inputs of the above fields

This informs the user of the results calculated from their inputs of the above fields

This informs the user of the results calculated from their inputs of the above fields

This informs the user of the results calculated from their inputs of the above fields

This informs the user of the results calculated from their inputs of the above fields

This informs the user of the results calculated from their inputs of the above fields 


\section{(1) 0 (i)}

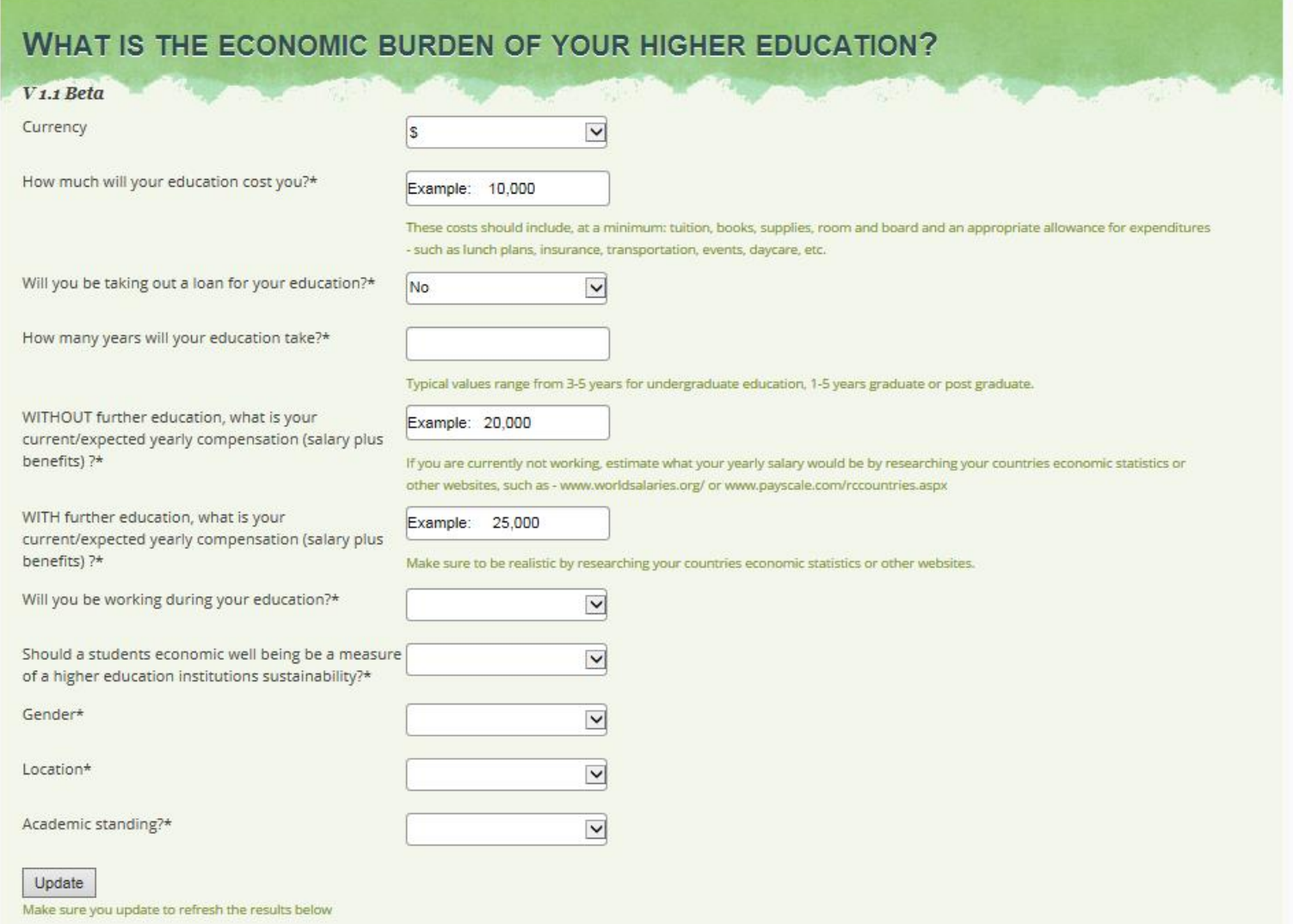

Figure 2. Calculator Inputs screen shot

\subsection{Data Collection}

A period of two months, from November 15, 2015, through January 15, 2016, was allowed for data collection in which the calculator widget gathered data from users while website statistics were tracked for unique visitors and pages visited. A digital campaign was initiated in December 20, 2015. The campaign consisted of posting on social websites such as Facebook and LinkedIn and an email to 110 people on December 20, 2015.

\section{Results}

\subsection{Website Results}

After the two month period, a total of 654 unique visitors visited the website and generated with 663 page views. The calculator page was by far the most popular generating 430 views, with the assessment page generating 120 views, the home page generating 99 views while the resources page generated 14 views. The calculator during the two month period collected data from 408 responses.

\subsection{Calculator Results}

Responses were received from all over the world but the majority of responses were from North America and Europe as is seen in Table 2 below.

Table 3. Respondents by continent

\begin{tabular}{lll}
\hline Continent & Responses & $\%$ of Responses \\
\hline Africa & 4 & $1 \%$ \\
Asia & 15 & $4 \%$ \\
Europe & 125 & $31 \%$ \\
North America & 195 & $48 \%$ \\
South America & 69 & $17 \%$ \\
\hline Total & 408 & $100 \%$ \\
\hline
\end{tabular}


Respondents represented a wide range of student stakeholders, namely future students, current students, or professionals considering to pursue higher education. Respondents have consistently supported that student economic well-being should be a measure of a higher education institutions sustainability as seen in Table 3 . It is noteworthy that the ratio of $90 \%$ in favor to $10 \%$ opposed has been collected by this research is also supported by the data collected from Maragakis \& Dobbelsteen (2013) and Maragakis et al. (2016b).

Table 4. Responses on the inclusion of economic metrics in an institutions level of sustainability

\begin{tabular}{llc}
\hline Answer & $\begin{array}{l}\text { Responses to "Should a student's economic well-being be a measure of a higher } \\
\text { education institutions sustainability?" }\end{array}$ & $\%$ of Respondents \\
\hline No & 43 & $11 \%$ \\
Yes & 365 & $89 \%$ \\
\hline
\end{tabular}

As would be expected, respondents expected a relative increase in salary from finishing higher education, as shown below in Table 4.

Table 5. Expected average increase in salary after completing higher education

\begin{tabular}{ll}
\hline Continent & Expected average increase in salary after completing higher education \\
\hline Africa & $381 \%$ \\
Asia & $244 \%$ \\
Europe & $159 \%$ \\
North America & $174 \%$ \\
South America & $252 \%$ \\
\hline
\end{tabular}

The results in Table 4 show a clear expectation that higher education should bring significant economic returns. This is aligned with the OECD (2012) analysis that shows that the net present value of undertaking higher education is positive.

Table 6. Absolute Repayment Period

\begin{tabular}{ll}
\hline Continent & Absolute Repayment of Higher education (years) \\
\hline Africa & 1.2 \\
Asia & 2.1 \\
Europe & 5.7 \\
North America & 4.6 \\
South America & 1.9 \\
\hline
\end{tabular}

The absolute repayment period in Table 5 was calculated on by taking the total burden of higher education divided by the average expected increase in wages. From a strictly investment point of view, the perceived returns of higher education offer a strong financial investment. The perceived increase in salary, if allocated $100 \%$ to repaying the total burden of the degree, would be expected to repay the investment in less than six years in the worst case scenario. It is interesting to note that Africa, Asia and South America expect a much lower [period of repayment than the North America and Europe.

However, allocation of $100 \%$ of gains is neither supports the requirements of stakeholders nor is sustainable. Maragakis et al. (2016b) identified that more than $90 \%$ of stakeholders expected that education should cost less than $15 \%$ of their future wages while payback should be in less than 10 years. While this was stakeholder perception, a more realistic and sustainable repayment should be considered at 8\%. Baum \& O'Malley (2003) pointed out that an exact level of acceptable debt burden is not formally defined, but they suggest a benchmarks of $8 \%$. In fact, some research shows that anything above $8 \%$ is considered unmanageable and at increased risk of default (Gross et al., 2009). 
Table 7. Repayment duration in year for $8 \%$ and $15 \%$ payback of expected future salary

\begin{tabular}{lll}
\hline Continent & $\begin{array}{c}\text { Years to repay higher education at } \\
8 \% \text { of future expected salary }\end{array}$ & $\begin{array}{c}\text { Years to repay higher education at } 15 \% \text { of } \\
\text { future expected salary }\end{array}$ \\
\hline Africa & 12.0 & 6.4 \\
Asia & 15.2 & 8.1 \\
Europe & 40.8 & 16.6 \\
North America & 29.9 & 17.8 \\
South America & 14.6 & 7.8 \\
\hline
\end{tabular}

In terms of the majority of stakeholder preferences, the data in Table 6 shows that North American and Europeans did not meet the ten-year payback expectation at $15 \%$ repayment. However, in terms of repayment at a sustainable level, no single continent average was below the ten year payback period.

Table 8. Expected loans by continent

\begin{tabular}{lll}
\hline Continent & Yes & No \\
\hline Africa & 2 & 4 \\
Asia & 80 & 13 \\
Europe & 83 & 45 \\
North America & 22 & 112 \\
South America & 187 & 47 \\
\hline Total & in & 221
\end{tabular}

It is noteworthy that the data in Table 7 shows that there is a relatively equal split between respondents expecting to take on a loan for higher education. $46 \%$ indicated that they were going to assume a loan while $54 \%$ indicated that they were not.

\section{Conclusions and Discussion}

\subsection{Conclusion: is a Student's Economic Well-being a Measure of a Higher Education Institution's Sustainability?}

The primary point of this research was to verify if economics metrics should be included when assessing a higher education institutions level of sustainability. This was tested both by directly asking stakeholder and also gathering information to determine unsustainable trends.

The data collected showed that $89 \%$ of respondents agreed that a student's economic well-being is a measure of a higher education institution's sustainability. This strong response is not unique considering equally strong responses to Maragakis \& Dobbelsteen (2013) and Maragakis et al. (2016b). What is interesting to note is that in all these studies, around $90 \%$ of respondents have supported economic metrics in sustainability assessment. These three studies were conducted with different audiences, in different years and utilizing slightly different criteria but they all point to an overwhelming support of the inclusion of economic parameters in sustainability assessments of higher education institutions. Considering that students are the ultimate client of these assessments, their repeated needs should be considered and implemented.

In terms of economic realities, respondents seemed to accurately understand the relative returns of higher education. The expected returns from European and North American students seemed to be realistic when compared to OECD (2012) numbers. While the understanding of the gains was well understood, the reality of sustainably paying back this debt was not.

At an absolute level, higher education provides a strong repayment when the relative gains are used to offset the incurred debt. However individuals do not respond to the debt this way, with $90 \%$ of respondents wanting to allocate a maximum of $15 \%$ of their future earnings to debt repayment. Based on this expectations, North Americans and European would find themselves in debt for longer than the maximum ten years they would be willing to tolerate. But these are their expectations and not reality.

Using the benchmark maximum acceptable repayment of 8\% (Baum \& O'Malley, 2003; Gross et al., 2009), all stakeholder took more than 10 years to payback their economic burden. Even more troubling, Europeans and North Americans remained in debt for decades. This payback period is definitely well beyond the expectations and 
perceptions of stakeholders. Furthermore, it essentially puts the $46 \%$ of respondents taking out loans in either an unsustainable situation where they will be repaying debt for the majority of their lives or a situation where they will have to default on their loans. The data supports claims by Noam Chomsky that high tuition acts as a debt trap that sharply restricts choices after graduation (Chomsky, 2013). This data also highlights the need for the inclusion of economic metrics in sustainability assessments.

While this study is empirical, the data strongly supports that economic well-being of graduates should be included as a metric for sustainability in higher education institutions. Firstly, in this research, as in other previous research, it has been overwhelmingly requested by stakeholders. Beyond the stakeholders wants though, this research has put quantifiable data against perceptions and realities and shown that the majority of stakeholders will either be in debt for decades to come or have to default on loans, both of which are unsustainable for the individuals and society.

With this in mind, higher education institutions that are claiming to be sustainable need to include the economic metrics in their assessments and marketing materials. On the fundamental principal of sustainability, a university should not claim to be sustainable if it is placing an unsustainable debt on its graduates.

\subsection{Discussion on Limitation and Uncertainties}

Due to this methodology, there is the potential for promoting bias in the results. The promotion of the survey through digital media may promote bias based on the researcher's contacts and groups. Although the survey was promoted on various sites, there may have been a tendency to receive more responses from technical rather than social science stakeholders.

The results are also limited in their usefulness due to their empirical nature and limited international perspective. The data collected primarily represented North America and Europe. Furthermore, the data set also showed a tendency for Europeans being graduate respondents while North Americans being first time students.

While the ratio of calculator responses to unique visitors was 408/430, unique responses could not be tracked. Each time the response the calculator collected did not track unique IP addresses which means that the data collected may not be from 408 unique sources and contain multiple scenarios from the same user.

\subsection{Recommendations}

The results show that economic metrics should be included as a metric of sustainability, but show that the exact economic burden rate is still not formally defined. Further research on what an acceptable debt level should be for inclusion in sustainability metrics should be explored.

\section{References}

Ashford, N. A., Hall, R. P., \& Ashford, R. (2012). Addressing the Crisis in Employment and Consumer Demand: Reconciliation with Financial and Environmental Sustainability. The European Financial Review, October-November 2012, 63-68.

Bell, D. N. F. \& Blanchflower, D.G. (2011). Underemployment in the UK in the Great Recession. National Institute Economic Review, No. 215. http://dx.doi.org/10.1177/0027950111401141

Bone, E., \& Agombar, J. (2011). First-year attitudes towards, and skills in, sustainable development. The Higher Education Academy.

Baum, S. \& O'Malley, M. (2003). College on Credit: How Borrowers Perceive Their Education Debt. Journal of Student Financial Aid, 33(3). http://publications.nasfaa.org/jsfa/vol33/iss3/1

Carroll, D. \& Tani, M. (2013). Over-education of recent higher education graduates: New Australian panel evidence. Economics of Education Review, 32, 207-218. http://dx.doi.org/10.1016/j.econedurev.2012.10.002

Chomsky, N. Interviewed by Grujicic, S. (2013). The Lab magazine, July 15, 2013. https://chomsky.info/20130715/

Gross, J., Cekic, O., Hossler, D. and Hillman, N. (2009). What Matters in Student Loan Default: A Review of the Research Literature. Journal of Student Financial Aid, 39(1), 19-29.

Linsley, I. (2005). Causes of overeducation in the Australian labour market. Australian Journal of Labour Economics, $8(2), 121-143$.

Maragakis, A., Dobbelsteen, A. (2013). Higher Education: Features, Trends and Needs in Relation to Sustainability. Journal of Sustainability Education, The Institute for Sustainable Social Change.

Maragakis, A., Dobbelsteen, A. (2015). Sustainability in Higher Education Analysis and Selection of Assessment Systems. Journal of Sustainable Development, 8(3). http://dx.doi.org/10.5539/jsd.v8n3p1 
Maragakis, A., Dobbelsteen, A. and Maragakis, Al. (2016a). Is Higher Education Economically Unsustainable? An Exploration of Factors that Undermine Sustainability Assessments of Higher Education, Discourse and Communication for Sustainable Development, 7(1).

Maragakis, A., Dobbelsteen, A. \& Maragakis, Al. (2016b). Earning Capacity of Sustainable Education - A Review of Current Perceptions Regarding the Salaries, Under-employment and Over-education of Higher-Education Graduates and their Potential Application in Sustainability Assessments, Journal of Sustainable Development; 9(3). http://dx.doi.org/10.5539/jsd.v9n3p261

OECD. (2011). Education at a Glance 2011: OECD Indicators, OECD Publishing. http://dx.doi.org/10.1787/eag-2011-en

OECD. (2012) Education Indicators in Focus. June, 2012. http://dx.doi.org/10.1787/22267077

Penn State Green Destiny Council (2000). Penn State Indicators Report 2000: Steps Toward a Sustainable University. State College, PA.

Psacharopoulos, G. \& Patrinos, H. A. (2004) Returns to Investment in Education: A further Update. Education Economics, 12(2). http://dx.doi.org/10.1080/0964529042000239140

Rajecki, D., \& Borden, V. M. (2011). Psychology Degrees: Employment, Wage, and Career Trajectory $\begin{array}{lllll}\text { Consequences. } & \text { Perspectives on }\end{array}$ http://dx.doi.org/10.1177/1745691611412385

Rothstein, J. and Rouse, C. E., (2011). Constrained after college: Student loans and early-career occupational choice. Journal of Public Economics, 95, 149-163. http://dx.doi.org/10.1016/j.jpubeco.2010.09.015

Saadatian, O., Dola, K. B., Tahir, O. M. (2011). Identifying Strengths and Weakness of Sustainable Higher Educational Assessment Approaches. International Journal of Business and Social Science, 2(3), 137-146.

Shriberg, M. (2002). Institutional assessment tools for sustainability in higher education: strengths, weaknesses, and implications for practice and theory. Higher Education Policy, 15(2), 153-167. http://dx.doi.org/10.1108/14676370210434714

The Talloires Declaration. (1990). Tufts European Center, Talloires, France: Proc., Rep. and Declaration of the Presidents Conference.

UNESCO (2011). Education for Sustainable Development. http://www.unesco.org/new/en/education/themes/leading-the-international-agenda/education-for-sustainable-de velopment/

Usher, A. \& Medow, J. (2010). Global Higher Education Rankings 2010: Affordability and Accessibility in Comparative Perspective. Higher Education Strategy Associates. 